\title{
Prevalence and Management Outcome of Patients Underwent Vaginal Hysterectomy in Gynecology Ward of Jimma University Medical Center, Southwest Ethiopia
}

\author{
Yibeltal Siraneh ${ }^{1 *}$ and Ahadu Workneh ${ }^{2}$ \\ ${ }^{1}$ Department of Health Economics, Management and Policy, Jimma University, Ethiopia \\ ${ }^{2}$ Department of Obstetric and Gynecology, Jimma University, Ethiopia
}

Submission: September 09, 2018; Published: December 07, 2018

*Corresponding author: Yibeltal Siraneh Belete, Department of Health Economics, Management and Policy, Jimma University, Ethiopia

\begin{abstract}
Background: Pelvic organ prolapse is one of the major gynecologic problems which affect the quality of life of many women worldwide, especially of old ages. Though there are different ways of managing apical pelvic organ prolapse, vaginal way is the main stay of surgical treatment in most of the cases. Vaginal hysterectomy is one of the most frequently performed surgical procedures worldwide. Step by step surgical procedure has been applied in JUMC by subspecialty fellows starting from 2016 . However, there is no study conducted on prevalence, management outcome and description of cases with respective procedure performed. Hence, the objective of this study is to determine prevalence, surgical outcome, and describe step by step surgical procedure of vaginal hysterectomy among patients who were admitted and treated at gynecology ward, Jimma University Medical center.
\end{abstract}

Method: A cross-sectional descriptive study design was used on all patients who have undergone vaginal hysterectomy at JUMC gynecology ward from Nov 01, 2016 to May 30, 2018 retrospectively. The data collection period was from July 01-15, 2018. Data was collected using pretested structured questionnaire to capture all necessary information from patients' chart. Trained residents abstracted the data from the chart. The collected data was entered into Epidata version 3.1 and was exported to SPSS versions 21 for cleaning and analysis. Finally the finding was presented using tables, narratives and descriptive numerical summary. Mean, median and standard deviations were also used to describe continuous variables. All ethical issues were considered including ethical approval from IRB of Institute of health, Jimma University.

Result: Out of all patients treated with vaginal hysterectomy, 43 (52.4\%) were above 49 years. The mean age was 48.37 years (SD 11) with range of 25 to 70 years. Out of all patients (92) who presented with POP, 82 of them treated with vaginal hysterectomy accounts $89.13 \%$ prevalence of VAGH treatment for POP. More than half 47 (57.3\%) were sexually active, and 44 (53.7\%) of them lived with POP for more than 120 months. More than two-third $56(68.3 \%)$ were presented at the final stage of POP with stage four but less than half presented with stage four for apical POP. Nearly all $79(96.3 \%)$ of them the procedure took two to three hours in which the approach is vaginally for all. For 54 (65.9\%), 72 (87.8\%),71 (86.6\%), 70 (85.4\%) patients anterior repair with colpo-suspension, anterior repair, posterior repair and perineorraphy done. However, for no one open uterosacral ligament suspension and open abdomino-sacrocolpopexy done. Four of patients were faced post-operative complication, three faced post-operative hemorrhage and four of them face problem of urinary retention which are all categorized as an unfavorable outcome.

Conclusion: Out of all patients presented with POP, nearly all of them treated with vaginal hysterectomy which shows high prevalence of VAGH. Most of the patients end up their procedure with favorable outcome. In our study, majority of patients had stage 3 and 4 AVWP and apical prolapse based on Simplified Pelvic organ prolapse quantification (S-POPQ). The final stage of prolapse (all compartments) is stage 3-4 in majority of patients. The mean duration of surgery for all cases of POP is $114( \pm 36)$ minutes.

Keywords: Prevalence; Outcome; Description of surgical procedure; Vaginal hysterectomy; JUMC

Abbreviation: CI-Confidence Linterval; JUMC: Jimma University Medical Center; NIH: National Institutes of Health; OR: Odds Ratio; POP: Pelvic Organ Prolapse; QOL: Quality of Life; US: United States; UVP: Utero Vaginal prolapse; VAG: Vaginal; VAGH: Vaginal Hysterectomy

\section{Background of the Study}

Pelvic organ prolapse is one of the major gynecologic problems which affect the quality of life of many women worldwide, especially of old ages. Though there are different ways of manag ing apical pelvic organ prolapse, vaginal hysterectomy is the main stay of surgical treatment in most of the cases which is frequently performed surgical procedure worldwide [1]. 


\section{Journal of Gynecology and Women's Health}

In Sweden, at least $15 \%$ of women over the age of 40 years suffer from vaginal prolapse or urinary incontinence [2-3]. The incidence of pelvic organ prolapse increases with age, and by age 80 a woman's lifetime risk of undergoing a single operation for prolapse or urinary incontinence is $11 \%$, with a $29 \%$ risk of reoperation. As the population ages, the need for medical care for uterine or vaginal prolapse will probably increase [4].

Vaginal hysterectomy is one of several surgical procedures for the correction of symptomatic prolapse. Reported benefits of vaginal hysterectomy compared to abdominal hysterectomy in the U.S. include shorter duration of hospital stay (WMD 1.0 day, 95\% CI: 0.7 to 1.2 days), speedier return to normal activities (WMD 9.5 days, $95 \%$ CI: 6.4 to 12.6 days), and fewer unspecified infections or febrile episodes (OR 0.42, 95\% CI: 0.21 to 0.83 ) (1). The lifetime risk of undergoing pelvic floor surgery is estimated to $11 \%$ [5].

The goals of surgery for pelvic organ prolapse should be relief of symptoms. Most studies evaluating outcomes of POP surgery have focused exclusively on anatomical success [6]. Due to the lack of standardized definitions for success of treatment following POP surgery, the National Institutes of Health (NIH) Workshop on Standardization of Terminology for Pelvic Floor Disorders recommended the following definitions for treatment success: 'optimal anatomical outcome' (POP-Q stage 0) and 'satisfactory anatomical outcome' (POP-Q stage I) [7]. Definitions of vaginal prolapse that include the absence of vaginal bulge symptoms have the strongest relationships with patients' own assessment of improvement and treatment success, and are more clinically relevant [8].

Vaginal hysterectomy is one of the sugical procedure which had been applied on case by case bases in JUMC by sub-specialty fellows starting from 2016 to treat cases with pelvic organ prolapse. However, there is no study conducted on prevalence, outcome and description of cases with respective technical/ surgical procedure performed. Hence, the objective of this study was to determine prevalence, surgical outcome, and describe step by step surgical procedure including special equipment among patients who were treated with vaginal hysterectomy at JUMC.

\section{Statement of the Problem}

In Sweden, at least $15 \%$ of women over the age of 40 years suffer from vaginal prolapse or urinary incontinence [2-3]. The incidence of pelvic organ prolapse increases with age, and by age 80 a woman's lifetime risk of undergoing a single operation for prolapse or urinary incontinence is $11 \%$, with a $29 \%$ risk of reoperation [4]. As the population ages, the need for medical care for uterine or vaginal prolapse will probably increase. Vaginal hysterectomy is one of several surgical procedures for the correction of symptomatic prolapse. Reported benefits of vaginal hysterectomy compared to abdominal hysterectomy in the U.S. include shorter duration of hospital stay (WMD 1.0 day, 95\% CI: 0.7 to 1.2 days), speedier return to normal activities (WMD 9.5 days, $95 \%$ CI: 6.4 to 12.6 days), and fewer unspecified infections or febrile episodes (OR $0.42,95 \%$ CI: 0.21 to 0.83 ) [1]. The lifetime risk of undergoing pelvic floor surgery is estimated to $11 \%$ [5].
Outcome measures are tools used to determine the efficacy and side effects of a treatment. POP is a multi-dimensional phenomenon, and success of treatment is often difficult to define. However, most studies have focused on anatomical success without considering symptoms and the quality of life (QOL) of the patient. In most studies in this field, outcomes of surgery have been assessed using questionnaires evaluating the efficacy of treatment regarding symptoms, sexuality, and QOL. In Scandinavia, condition-specific questionnaires for POP and UI have been developed for identification of these disorders and for assessment of the subjective cure [8].

Due to the lack of standardized definitions for success of treatment following POP surgery, the National Institutes of Health (NIH) Workshop on Standardization of Terminology for Pelvic Floor Disorders recommended the following definitions for treatment success: 'optimal anatomical outcome' (POP-Q stage 0) and 'satisfactory anatomical outcome' (POP-Q stage I). However, $75 \%$ of women presenting for annual gynecological examination without symptoms of POP will not meet the definition of 'optimal anatomical outcome' and almost $40 \%$ will not meet the definition of 'satisfactory anatomical outcome' [5,7].

Publications with the lowest success rates have defined success as more stringent anatomical outcomes while studies with the highest success rates have generally used subjective outcomes such as satisfaction and relief of symptoms of POP. Definitions of vaginal prolapse that include the absence of vaginal bulge symptoms have the strongest relationships with patients' own assessment of improvement and treatment success, and are more clinically relevant [8].

A study revealed that almost $60 \%$ of women reported normal activity of daily life (ADL) within one week of surgery, irrespective of their age. Severe complications occurred in 3\% and were mainly intraabdominal bleeding and vaginal vault hematomas. Six months postoperative, sexual activity had increased for $20 \%$ $(p=0.006)$ of women and urinary urgency was reduced for $50 \%$ $(\mathrm{p}=0.001)$; however, $14 \%(\mathrm{n}=76)$ of women developed urinary incontinence, $76 \%(n=58)$ of whom reported urinary stress incontinence. Patients were satisfied with the postoperative result in $93 \%$ of cases and $94 \%$ recommended the surgery. This study concluded and recommended that Vaginal hysterectomy is a patient-evaluated efficient treatment for uterovaginal prolapse with swift recovery and a low rate of complication. Sexual activity and symptoms of urinary urgency were improved. However, $14 \%$ developed incontinence, mainly urinary stress incontinence (11\%). Therefore efforts to disclose latent stress incontinence should be undertaken preoperatively. Hence, the problem in this regard is no study conducted on prevalence, outcome and description of cases with respective new technical/surgical procedure performed in the study area's setting (JUMC).

\section{Literature Review}

\section{Over view of literature review}

Many litrature reviewed to conceptualize the prevalence, management outcome and related concepts about vaginal hyster- 
ectomy as an option to treat utero-vaginal prolapse. Even if there is contiroversy regaring this optional treatment's advantage and disadvantage, this study only review the cases managed in such a way. Hence, this section organized and presented as follows.

\section{Prevalence of vaginal hysterectomy}

In Sweden, at least $15 \%$ of women over the age of 40 years suffer from vaginal prolapse or urinary incontinence [2-3]. The incidence of pelvic organ prolapse increases with age, and by age 80 a woman's lifetime risk of undergoing a single operation for prolapse or urinary incontinence is $11 \%$, with a $29 \%$ risk of reoperation [4]. As the population ages, the need for medical care for uterine or vaginal prolapse will probably increase. Vaginal hysterectomy is one of several surgical procedures for the correction of symptomatic prolapse. Reported benefits of vaginal hysterectomy compared to abdominal hysterectomy in the U.S. include shorter duration of hospital stay (WMD 1.0 day, 95\% CI: 0.7 to 1.2 days), speedier return to normal activities (WMD 9.5 days, $95 \%$ CI: 6.4 to 12.6 days), and fewer unspecified infections or febrile episodes (OR 0.42, 95\% CI: 0.21 to 0.83 ) [1]. The lifetime risk of undergoing pelvic floor surgery is estimated to $11 \%$ [5].

\section{Management outcome of vaginal hysterectomy}

In 1966 Williams, described a technique for transvaginal uterosacral-cervical ligament plication. He reported on the outcomes of 20 women undergoing this procedure, with three 'failures' encountered within a 6-month follow-up period. His method involved a posterior colpotomy with division of the uterosacral ligaments from the cervix, plication across the midline and reinsertion into the cervix. The cardinal ligaments are then plicated anteriorly across the midline [9].

The concept of sacrospinous hysteropexy was first described by Richardson in 1989. The cervix or uterosacral ligament is transfixed to the sacrospinous ligament using either permanent or delayed absorbable sutures [10]. In 2001 Maher, reported a small comparison study between sacrospinous hysteropexy and vaginal hysterectomy with sacrospinous vault fixation, with no differences in objective or subjective outcomes at follow-up [11]. Other studies have suggested that sacrospinous hysteropexy has a shorter operative time and less blood loss than vaginal hysterectomy [12]. One study also reported fewer postoperative incidences of overactive bladder symptoms in the sacrospinous hysteropexy group [13]. Dietz et al, described an increased risk of anterior compartment prolapse following sacrospinous hysteropexy, with an incidence of up to $40 \%$. Sacrospinous hysteropexy, is the most studied vaginal technique for uterine preservation prolapse surgery; however, in general, the studies assessing it are of poor quality, with small numbers, short follow-up periods [14]. The technique of posterior vaginal slingplasty was first described in 2001, using a mesh kit to create 'neo-utero-sacral ligaments. One prospective comparison study quoted a $91.4 \%$ patient satisfaction rate post-surgery, but cumulative data suggest a high incidence of mesh complications with up to a $21 \%$ mesh erosion rate [15-17].

Outcome measures are tools used to determine the efficacy and side effects of a treatment. POP is a multi-dimensional phenomenon, and success of treatment is often difficult to define. However, most studies have focused on anatomical success without considering symptoms and the quality of life (QOL) of the patient. In most studies in this field, outcomes of surgery have been assessed using questionnaires evaluating the efficacy of treatment regarding symptoms, sexuality, and QOL. In Scandinavia, condition-specific questionnaires for POP and UI have been developed for identification of these disorders and for assessment of the subjective cure $[8,18]$.

Due to the lack of standardized definitions for success of treatment following POP surgery, the National Institutes of Health (NIH) Workshop on Standardization of Terminology for Pelvic Floor Disorders recommended the following definitions for treatment success: 'optimal anatomical outcome' (POP-Q stage 0) and 'satisfactory anatomical outcome' (POP-Q stage I). However, $75 \%$ of women presenting for annual gynecological examination without symptoms of POP will not meet the definition of 'optimal anatomical outcome' and almost $40 \%$ will not meet the definition of 'satisfactory anatomical outcome' $[5,7]$.

Publications with the lowest success rates have defined success as more stringent anatomical outcomes while studies with the highest success rates have generally used subjective outcomes such as satisfaction and relief of symptoms of POP $[11,19]$. Definitions of vaginal prolapse that include the absence of vaginal bulge symptoms have the strongest relationships with patients' own assessment of improvement and treatment success, and are more clinically relevant [8].

A study revealed that almost $60 \%$ of women reported normal activity of daily life (ADL) within one week of surgery, irrespective of their age. Severe complications occurred in 3\% and were mainly intraabdominal bleeding and vaginal vault hematomas. Six months postoperative, sexual activity had increased for $20 \%$ $(p=0.006)$ of women and urinary urgency was reduced for $50 \%$ $(\mathrm{p}=0.001)$; however, $14 \%(\mathrm{n}=76)$ of women developed urinary incontinence, $76 \%(\mathrm{n}=58)$ of whom reported urinary stress incontinence. Patients were satisfied with the postoperative result in $93 \%$ of cases and $94 \%$ recommended the surgery [20]. This study concluded and recommended that Vaginal hysterectomy is a patient-evaluated efficient treatment for uterovaginal prolapse with swift recovery and a low rate of complication. Sexual activity and symptoms of urinary urgency were improved. However, $14 \%$ developed incontinence, mainly urinary stress incontinence (11\%). Therefore efforts to disclose latent stress incontinence should be undertaken preoperatively [20].

\section{Objective of the Study}

\section{General objective}

A. To determine the prevalence and outcome of UVP patients treated with vaginal hysterectomy retrospectively (November 01, 2016 to May 30, 2018) at Gynecology ward, JUMC.

\section{Specific objectives}

a) To describe the course of events (surgical techniques ) of vaginal hysterectomy done for UVP 
b) To determine the prevalence of UVP patients treated with vaginal hysterectomy

c) To assess surgical outcome of UVP patients treated with vaginal hysterectomy

\section{Methods and Participants}

\section{Study area and period}

The study was undertaken in Jimma University Medical Center (JUMC). The center is found in Jimma, Oromia Regional state, Southwest Ethiopia. The data collection period was from July 0115, 2018. Jimma town is found at 352KMs from Addis Ababa, the capital city of Ethiopia, in the South western part of the country. There are two public hospitals found in the town which are called JUMC and Shenen gibe primary hospital. JUMC has a catchment population of about 15 million people which expected to serve. The center has annual out-patient case load of 160, 000 and 45, 000 in-patients. It provides services to diverse population from three regional states; namely, Oromia, Southern Nations, Nationalities and Peoples, and Gambella.

Jimma university medical center is one of the oldest public hospitals in the country. It was established in 1930 E.C by Italian invaders for the service of their soldiers. After the withdrawal of the colonial occupants, it has been governed under the Ethiopian government by the name of Ras desta damtew hospital and latter Jimma hospital during dergue regime after the down fall the dergue until 2009 E.C the name was Jimma University specialized teaching hospital and currently its name is changed to Jimma university medical center.

Jimma university medical center is committed to reduce morbidity, mortality, disability and improve health status of the local people through providing a compressive package of high quality curative, preventive, promotive, and rehabilitative health service to the public and providing clinical education to physicians, nurses, medical laboratory technologists, pharmacists and other clinical and public health students in collaboration with respective stakeholder.

It has a total of 1846 servants from which 827 are technical staffs (health professional), 766 are administrative staff and the remaining 253 are temporary staffs. JUMC categorized in to different departments (units) which is suitable for service provision like medical ward, surgical ward, pediatrics ward, maternity ward, gynecology ward, stroke unit, major OR, minor OR, neonatology ward, oncology ward, dialysis unit, psychiatry ward, maxillofacial ward, orthopedic OR, maternity OR, ophthalmology ward, ART Unit, chronic illness/derma ward, physiotherapy unit, gynecology OPD, pediatrics OPD, EOPD, cold OPD, CSR unit, Recovery unit, orthopedics ward, dental unit, ICU unit, Endoscopy unit and sexual violence clinic.

The gynecology ward is one of the unit under Obs/Gynecology department, accordingly, there were 92 numbers of cases got the service for pelvic organ prolapse through different types of surgical procedures from Nov 01, 2018-May 30, 2018.

\section{Study design}

Facility based retrospective cross sectional descriptive study design was used.

\section{Source population}

All cases admitted and treated with different type of procedure for pelvic organ prolapse in Gynecology ward,JUMC in the last one and half years period.

\section{Study population}

All cases treated with vaginal hysterectomy only for pelvic organ prolapse in Gynecology ward, JUMC in the last one and half years period.

\section{Eligibility criteria}

Only those case treated with the new surgical technique of vaginal hysterectomy for UVP was included. Otherwise, Those cases treated with any other type of surgical technique including undefined surgical method were excluded from the study.

\section{Sample size determination and sampling procedure}

Since the source population (92) is not more than 100 and for the sake of maximizing the sample size to have a good discription, all eligible cases was included in the study. All the charts available within the specified period was collected consecutively and those charts that may not fulfil the inclusion criteria were excluded before abstracting the required information.

\section{Study Variables}

a) Socio-demographic characteristics (Age, Marital status, Residency)

b) Obstetric history related variables (Gravidity, Parity, Menses)

c) Gynecology related variables (Hemoglobin, type of prolapse, any known gynecological/medical disease, duration of prolapse, menopause)

d) Clinical assessment and diagnostic procedure related variables (Stage of prolapse at entry, type of syptoms (local/vaginal, Urinary, bowel \& sexual)

e) Surgical procedure related variables (Type of procedure employed, type of equipment used, type of technique applied, duration of the procedure)

f) Management outcome related variables (hemorrhage/blood loss, improvement/death, Urinary syptoms (No syptom, urgency, urge \& stress incontinency), vaginal bulge symptoms, stage of prolapse at discharge).

\section{Methods of Data Collection}

\section{Data collection tool}

Structured checklist was developed by the researcher after reviewing relevant literature that can address the profile of patients who had undergoing surgical procedure of vaginal hysterectomy. The checklist was filled by chart review or data abstraction. 


\section{Data collection technique}

The data collectors were contacted the medical registry unit head to selected charts with vaginal hysterectomy cases using logbook as a directory. Then they excluded cases that may not fulfil the required inclusion criteria to the study. Finally, the data collectors abstracted the required information from the chart and complete the tool. All data collectors were responsible to return back the charts to the registry unit after finishing their work.

\section{Data collectors and supervisors}

Data collectors was recruited from JUMC Obs/gyn residents and was suppervised by senier Gyn/Obs specialists. Those residents and seniors who had involved in vaginal hysterectomy surgical procedure in the past 1 and half years were not recruited for data collection process.

\section{Method of data analysis}

The data was checked for completness, coded and entered into EPI data 3.1, and exported to SPSS version 21.0 for statistical analyses. Quantitative data was summarized in frequencies and proportions. Categorizing outcome assessing variables into two was done using the SPSS. Cross tabulation was used to compare different variables' distribution among cases. All apropraite discriptive data was displayed using centeral and dispersion statistics.

\section{Data quality management}

The data collection tool was pretested in St. Paulo's millennium medical college before the actual data collection. After pretest, the questionnaire was reviewed for appropriateness of wording; clarity of both contents and logical sequence of items in relation to patient chart order. Data collectors were trained for one day on the questionnaire to be familiar with. Editing and sorting of the questionnaires was done to check the completeness of data on daily bases. The completed questionnaires was cross checked and made correction on daily basis. I have used data entry and analysis software (Epidata3.1 and SPSS21) to minimize errors.

\section{Operetional definitions}

Stage of UVP: According to the newly introduced surgical procedure/technique, a simplified Pelvic Organ Prolapse Quantification (S-POPQ) was used to identify stage of prolapse. At discharge, S-POPQ was done to look into the stage of utero vaginal prolapse and this study also assessed the outcome of repair from the charts.

Management outcome: For the suitability and easy understanding in describing surgical outcome (short term) of vaginal hysterectomy, the following category was used.

a) Favorable management outcome

b) This is considered when there was no any complication at post-OP and if stage 1 or less POP recorded at discharge

\section{c) Unfavorable management outcome}

d) With Surgical difficulties, postoperative complication/s, and urine retention were considered as unfavorable health outcome whereas stage 2 or more POP after apical treatment was considered as unfavorable anatomical outcome.

Prevalence of vaginal hysterectomy was calculated using the source population (all cases treated with any type of surgical procedure) and all cases treated with vaginal hysterectomy, $\mathrm{P}=\mathrm{n} / \mathrm{N}$ Pelvic Organ Prolapse Quantification System (POP-Q) use descent of the anterior, posterior wall and the apex of the vagina (cervix/vaginal cuff) are measured using the hymen as the point of reference while the patient is straining. Five stages of vaginal prolapse are defined in the classification of POP-Q. Stage 0: No prolapse. Stage I: The most distal portion of the prolapse is $>1 \mathrm{~cm}$ above the level of the hymen. Stage II: The most distal portion of the prolapse is $\leq 1 \mathrm{~cm}$ proximal or distal to the hymen. Stage III: The most distal portion of the prolapse is $>1 \mathrm{~cm}$ below the hymen. Stage IV: Complete eversion of the total length of the lower genital tract is demonstrated.

\section{Ethical consideration}

Ethical clearance was obtained from Institutional Review Board (IRB) of Health Institute, Jimma University. Formal letter of request for cooperation was written to JUMC and respective offices including Obs/Gyn department. Since we did retrospective study, we assumed already study subjects gave their consent for clinical assessment and for further confidecial research dissemination. Hence, we planed to include only those charts signed by the respective client before they undergone the surgical procedure.

\section{Limitation of the study}

The data sources is secondary data (patient chart) which is limited to discribe all needed variables/information in this study, and reliability is depend on the physician who wrote the note in the chart. Additionally, all important variables relevant to this study were not captured due to incompleteness of the patient charts and absence of formats with it especially for socio-demographic data.

\section{Result}

\section{Socio-demographic characteristics}

Out of all patients treated with vaginal hysterectomy, more than half $43(52.4 \%)$ of them were above 49 years. The mean age was 48.37 years (SD 11) with range of 25 to 70 years. More than two third 56 (68.29\%), 58(70.7\%) were married and live in rural area respectively. More than half 44 (53.7\%) of them were Grand multiparous before the occurrence of POP and 45 (54.9\%) were still Grand multiparous after developing POP and had 4-6 number of children. More than three fourth had no any known mental/ medical illness. (See table 1).

Table1: Socio-demographic related variables distribution among patients who treated with VGH for POP, JUMC, June 2018.

\begin{tabular}{|c|c|c|c|}
\hline Variable & Categories & $\mathbf{N}$ & $\%$ \\
\hline \multirow{2}{*}{ Age in years } & Reproductive age group $(<=49)$ & 36 & 47.6 \\
\hline & Menopause age group (>49) & 43 & 52.4 \\
\hline
\end{tabular}


Journal of Gynecology and Women's Health

\begin{tabular}{|c|c|c|c|}
\hline \multirow{4}{*}{ Marital status } & currently married & 56 & 68.29 \\
\hline & single & 7 & 8.54 \\
\hline & widowed & 18 & 21.95 \\
\hline & divorced/separated & 1 & 1.22 \\
\hline \multirow{2}{*}{ Residency } & Urban & 24 & 29.3 \\
\hline & Rural & 58 & 70.7 \\
\hline \multirow{5}{*}{ Parity before POP occurrence } & Nullipara & 1 & 1.2 \\
\hline & Primipara & 1 & 1.2 \\
\hline & Multipara & 32 & 39 \\
\hline & Grand-multpara & 44 & 53.7 \\
\hline & Great Grand-multipara & 4 & 4.9 \\
\hline \multirow{5}{*}{ Current parity after POP occurrence } & Nullipara & 1 & 1.2 \\
\hline & Primipara & 1 & 1.2 \\
\hline & Multipara & 31 & 37.8 \\
\hline & Grand-multpara & 45 & 54.9 \\
\hline & Great Grand-multipara & 4 & 4.9 \\
\hline \multirow{3}{*}{ Number of living children } & Low number of children (1-3) & 19 & 23.2 \\
\hline & Medium number of children (4-6) & 45 & 54.9 \\
\hline & High number of children $(>=7$ ) & 18 & 22 \\
\hline \multirow[t]{2}{*}{ Known mental/medical illness } & Yes & 14 & 17.07 \\
\hline & No & 68 & 82.93 \\
\hline \multirow{4}{*}{ If yes, known medical innless? } & Asthma & 1 & 7.14 \\
\hline & DM & 1 & 7.14 \\
\hline & HTN (including stage I to II) & 11 & 78.57 \\
\hline & RVI & 1 & 7.14 \\
\hline
\end{tabular}

\section{Gynecology related variables}

Out of all patients treated with VAG hysterectomy, near to all 78 (95.12\%) of them had no known risk factor for developing POP and in the same way they had no urinary incontinence symptoms. Only three of them had this symptom such as 2 with stress incontinence and 1 had presented with urge incontinence but no fecal incontinence of their stool. More than half 47 (57.3\%) were sexually active, and $44(53.7 \%)$ of them lived with POP for more than 120 months. Majority (51 (62.7\%) of them were in menopause stage during the development of their POP but one third of them were still not in menopause stage. Only 4 reported as they had history of previous hysterectomy. More than half 46 (56.1\%) and 27 (32.9\%) of them presented with stage four of anterior and posterior POP respectively. More than two-third 56 $(68.3 \%)$ were presented at the final stage of POP with stage four but less than half presented with stage four for apical POP. (See table 2).

Table 2: Gynecology (POP) related variables measured among patients treated with VAG hysterectomy, JUMC, June 2018.

\begin{tabular}{|c|c|c|c|}
\hline Variable & Categories & $\mathbf{N}$ & $\%$ \\
\hline \multirow{2}{*}{ Is there risk factor for POP } & Yes & 4 & 4.88 \\
\hline & No & 78 & 95.12 \\
\hline \multirow{2}{*}{ Do you have urinary incontinence } & Yes & 3 & 3.7 \\
\hline & No & 79 & 96.3 \\
\hline \multirow{3}{*}{ If yes what is the type of urinary incontinence } & stress incontinence & 2 & 66.67 \\
\hline & urge incontinence & 1 & 33.33 \\
\hline & No fecal incontinence of stool & 0 & 0 \\
\hline \multirow{2}{*}{ Are you sexually active? } & Yes & 47 & 57.3 \\
\hline & No & 35 & 42.7 \\
\hline
\end{tabular}


Journal of Gynecology and Women's Health

\begin{tabular}{|c|c|c|c|}
\hline \multirow{3}{*}{ If No, what was the reason? } & No partner & 17 & 48.57 \\
\hline & No interest & 16 & 45.71 \\
\hline & urinary/fecal incontinence or bulge & 2 & 5.72 \\
\hline \multirow{3}{*}{ Duration of POP } & Short duration $(<=60$ months $)$ & 25 & 30.5 \\
\hline & Medium duration(60-120months) & 13 & 15.9 \\
\hline & Long duration (>120months) & 44 & 53.7 \\
\hline \multirow{2}{*}{ Is she in menopause when develop POP } & Yes & 51 & 62.2 \\
\hline & No & 31 & 37.8 \\
\hline \multirow{5}{*}{ Duration of menopause after developing POP } & For 5years & 17 & 20.7 \\
\hline & For $10 \mathrm{yrs}$ & 15 & 18.3 \\
\hline & For 15yrs & 9 & 11 \\
\hline & For 20 or above yrs & 9 & 11 \\
\hline & Not reached at the age of menopause & 32 & 39 \\
\hline \multirow{2}{*}{ previous surgery done for POP or hysterectomy } & Yes & 4 & 4.88 \\
\hline & No & 78 & 95.12 \\
\hline \multirow{3}{*}{ Type of surgery done previously } & $\mathrm{VH}+\mathrm{AC}$ & 2 & 50 \\
\hline & $\mathrm{VH}+\mathrm{AC}+\mathrm{PC}$ & 1 & 25 \\
\hline & SSLF without hysterectomy & 1 & 25 \\
\hline \multirow{3}{*}{ what is the stage of anterior POP } & Stage two & 3 & 3.7 \\
\hline & Stage Three & 33 & 40.2 \\
\hline & Stage Four & 46 & 56.1 \\
\hline \multirow{4}{*}{ what is the stage of posterior POP } & Stage one & 6 & 7.3 \\
\hline & Stage Two & 26 & 31.7 \\
\hline & Stage three & 23 & 28 \\
\hline & Stage Four & 27 & 32.9 \\
\hline \multirow{2}{*}{ What is the final stage of POP? } & Stage three & 26 & 31.7 \\
\hline & Stage Four & 56 & 68.3 \\
\hline \multirow{4}{*}{ What is the stage of apical POP? } & Stage one & 1 & 1.2 \\
\hline & Stage Two & 5 & 6.1 \\
\hline & Stage three & 38 & 46.3 \\
\hline & Stage Four & 38 & 46.3 \\
\hline
\end{tabular}

\section{Intra-OP (procedure) related variables}

Table 3: Intra-OP (procedure) related variables measured among patients treated with VAG hysterectomy, JUMC, June 2018.

\begin{tabular}{|c|c|c|c|}
\hline Variable & Categories & $\mathbf{N}$ & $\%$ \\
\hline \multirow{3}{*}{ Duration of procedure in hours } & For 1 hour & 1 & 1.2 \\
\hline & For two to three hours & 79 & 96.3 \\
\hline & For three or more hours & 2 & 2.4 \\
\hline \multirow{2}{*}{ Approach of surgery } & Vaginal & 82 & 100 \\
\hline & Other & 0 & 0 \\
\hline \multirow{2}{*}{ was there anterior repair with colpo-suspension? } & Yes & 54 & 65.9 \\
\hline & No & 28 & 34.1 \\
\hline \multirow{2}{*}{ Was there anterior repair? } & Yes & 72 & 87.8 \\
\hline & No & 10 & 12.2 \\
\hline \multirow{2}{*}{ Was there posterior repair? } & Yes & 71 & 86.6 \\
\hline & No & 11 & 13.4 \\
\hline
\end{tabular}




\section{Journal of Gynecology and Women's Health}

\begin{tabular}{|c|c|c|c|}
\hline \multirow{2}{*}{ Was there rectal anterior plication? } & Yes & 7 & 8.5 \\
\hline & No & 75 & 91.5 \\
\hline \multirow{2}{*}{ Was there perineorraphy? } & Yes & 70 & 85.4 \\
\hline & No & 12 & 14.6 \\
\hline \multirow{2}{*}{ Was there vaginal apical treatment without kit? } & Yes & 71 & 86.6 \\
\hline & No & 11 & 13.4 \\
\hline \multirow{2}{*}{ If yes what is the type? } & uteosacralligament & 40 & 55.6 \\
\hline & sacrospiousligamentfixation(Rich & 31 & 44.4 \\
\hline \multirow{2}{*}{ Was there colpohysterectomy with myorraphy? } & Yes & 9 & 11 \\
\hline & No & 73 & 89 \\
\hline \multirow{2}{*}{ Was there open uterosacral ligament suspension? } & Yes & 0 & 0 \\
\hline & No & 82 & 100 \\
\hline \multirow{2}{*}{ Was there open abdomino-sacrocolpopexy? } & Yes & 0 & 0 \\
\hline & No & 82 & 100 \\
\hline \multirow{2}{*}{ Was there urinary incontinence procedure done? } & Yes & 1 & 1.22 \\
\hline & No & 81 & 99.99 \\
\hline \multirow{2}{*}{ If yes what type of incontinence surgery? } & facialsling & 1 & 100 \\
\hline & Other & 0 & 0 \\
\hline \multirow{2}{*}{ type of anesthesia used } & spinal & 79 & 96.3 \\
\hline & general & 3 & 3.7 \\
\hline \multirow{2}{*}{ Amount of blood loss } & Expected blood loss $(<800 \mathrm{ml})$ & 34 & 41.5 \\
\hline & More than expected $(>=800 \mathrm{ml})$ & 48 & 58.5 \\
\hline
\end{tabular}

Out of all patients treated with VAG hysterectomy, for nearly all $79(96.3 \%)$ of them the procedure took two to three hours in which the approach is vaginally for all. For 54 (65.9\%), 72 (87.8\%), 71 (86.6\%), 70 (85.4\%) patients anterior repair with colpo-suspension, anterior repair, posterior repair and perineorraphy done respectively. However, for 75 (91.5\%) of them rectal anterior

\section{Prevalence and Management outcome}

Table 4: Short term outcome (Post-OP) measuring variables among patients treated with VAG hysterectomy, JUMC, June 2018.

\begin{tabular}{|c|c|c|c|}
\hline Variable & Categories & $\mathbf{N}$ & $\%$ \\
\hline \multirow{2}{*}{ Was there procedure with surgical difficulties? } & Yes & 8 & 9.8 \\
\hline & No & 74 & 90.2 \\
\hline \multirow{6}{*}{ Duration of postoperative bladder catheterization in days? } & For 1 day & 29 & 35.4 \\
\hline & For 2 days & 38 & 46.3 \\
\hline & For 3 days & 7 & 8.5 \\
\hline & For 5 days & 3 & 3.7 \\
\hline & For 6 days & 1 & 1.2 \\
\hline & For 7 days & 4 & 4.9 \\
\hline \multirow{2}{*}{ Post-operative complications } & Yes & 4 & 4.9 \\
\hline & No & 78 & 95.1 \\
\hline \multirow{2}{*}{ Postoperative hemorrhage } & Yes & 3 & 3.7 \\
\hline & No & 79 & 96.3 \\
\hline \multirow{2}{*}{ urinary retention $>24$ hours } & Yes & 4 & 4.9 \\
\hline & No & 78 & 95.1 \\
\hline
\end{tabular}

plication was not done. For 71 (86.6\%) vaginal apical treatment without kit was there, among them for 40 (55.6\%) patients' uteosacralligament treatment given. However, for no one open uterosacral ligament suspension and open abdomino-sacrocolpopexy (58.5\%) of them bleed more than expected. (See table 3). done. Almost for all of them spinal anesthesia was given and 48 
Journal of Gynecology and Women's Health

\begin{tabular}{|c|c|c|c|}
\hline \multirow{2}{*}{ What was the surgery outcome at discharge? } & Improved & 82 & 100 \\
\hline & Not improved & 0 & 0 \\
\hline \multirow{3}{*}{ what is the stage of anterior POP at discharge } & Stage 0 & 19 & 23.17 \\
\hline & Stage one & 62 & 75.61 \\
\hline & Stage two & 1 & 1.22 \\
\hline \multirow{2}{*}{ What is the stage of posterior POP at discharge? } & Stage 0 & 19 & 23.17 \\
\hline & Stage one & 63 & 76.83 \\
\hline \multirow{3}{*}{ What is the stage of apical POP at discharge? } & Stage 0 & 19 & 23.17 \\
\hline & Stage one & 54 & 65.85 \\
\hline & Stage two & 9 & 10.98 \\
\hline \multirow{2}{*}{ What is the final stage of POP at discharge? } & Stage 0 (Favorable outcome) & 19 & 23.17 \\
\hline & Stage two (Unfavorable outcome) & 9 & 10.98 \\
\hline
\end{tabular}

Out of all patients (92) who presented with POP, 82 of them treated with vaginal hysterectomy which means $89.13 \%$ prevalence of VAGH treatment. Surgeon's procedure notes indicate that for $74(90.2 \%)$ patients, there was not surgical difficulty. Near to half 38 (46.3\%) of patients stayed with bladder catheter for 2 days. Four of patients were faced post-operative complication, three faced post-operative hemorrhage and four of them face problem of urinary retention which are all categorized as an unfavorable outcome. However, all of them (82) discharged with improvement. More specifically, 81 patients, 82 patients, 73patients and 73 patients had favorable outcome (stage 0 and Table 5: Three months follow up outcome (Post-OP follow up) measuring variables among patients treated with VAG hysterectomy, JUMC, June 2018.

\begin{tabular}{|c|c|c|c|}
\hline Variable & Categories & $\mathbf{N}$ & $\%$ \\
\hline \multirow{2}{*}{ Does the patient return for follow up at 3 months? } & yes & 23 & 28.05 \\
\hline & no & 59 & 71.95 \\
\hline \multirow{2}{*}{ Did the patient have complications? } & Yes & 5 & 21.74 \\
\hline & No & 18 & 78.26 \\
\hline \multirow{2}{*}{ What is the stage of anterior POP at 3 months? } & Stage one & 17 & 73.91 \\
\hline & Stage two & 6 & 26.09 \\
\hline What is the stage of posterior POP at 3 months? & Stage one & 17 & 73.91 \\
\hline \multirow{2}{*}{ What is the stage of apical POP at 3 months? } & Stage one & 15 & 88.2 \\
\hline & Stage two & 2 & 11.8 \\
\hline \multirow{2}{*}{ What is the final stage of POP at 3 months? } & Stage one & 15 & 88.2 \\
\hline & Stage two & 2 & 11.8 \\
\hline
\end{tabular}

\section{Discussion}

In this study, Out of all patients (92) who presented with POP, 82 of them treated with vaginal hysterectomy which accounts 89.13\% prevalence of patients treated with VAGH. In Sweden, at least $15 \%$ of women over the age of 40 years suffer from vaginal prolapse or urinary incontinence [2-3]. The incidence of pelvic organ prolapse increases with age, and by age 80 a woman's lifetime risk of undergoing a single operation for prolapse or urinary incontinence is $11 \%$, with a $29 \%$ risk of reoperation [4]. As the population ages, the need for medical care for uterine or vaginal prolapse will probably increase. This result is different from the
1) for anterior, posterior, apical and final stage of POP at discharge respectively. (See table 4).

\section{Three months follow up outcome}

Out of all patients treated with VAGH, only 23 of them were returned back for follow up. Among them only 5 had developed complications. For 17 patients, 17 patients, 15 patients and 15 patients had the stage of anterior, posterior, apical and final stage of POP was stage one at third months. Table 5. Three months follow up outcome (Post-OP follow up) measuring variables among patients treated with VAG hysterectomy, JUMC, June 2018. other studies reported which might be due to retrospective data used and the number of study subjects in our study is limited.

More than half 47 (57.3\%) were sexually active, and 44 (53.7\%) of them lived with POP for more than 120 months. More than two-third $56(68.3 \%)$ were presented at the final stage of POP with stage four but less than half presented with stage four for apical POP. Nearly all 79 (96.3\%) of them the procedure took two to three hours in which the approach is vaginally for all.

For 54 (65.9\%), for 72 (87.8\%), for 71 (86.6\%), for 70 (85.4\%) patients anterior repair with colpo-suspension, anterior repair, 
posterior repair and perineorraphy done respectively. However, for no one open uterosacral ligament suspension and open abdomino-sacrocolpopexy done. The concept of sacrospinous hysteropexy was first described by Richardson in 1989. The cervix or uterosacral ligament is transfixed to the sacrospinous ligament using either permanent or delayed absorbable sutures [10]. In 2001 Maher, reported a small comparison study between sacrospinous hysteropexy and vaginal hysterectomy with sacrospinous vault fixation, with no differences in objective or subjective outcomes at follow-up [11]. Other studies have suggested that sacrospinous hysteropexy has a shorter operative time and less blood loss than vaginal hysterectomy [12]. Still this result is defferent from the above studies revealed. Four of patients were faced post-operative complication, three faced post-operative hemorrhage and four of them face problem of urinary retention which are all categorized as an unfavorable outcome. However, other studies have suggested that sacrospinous hysteropexy has a shorter operative time and less blood loss than vaginal hysterectomy [12].

More specifically, 81 patients, 82 patients, 73patients and 73 patients had favorable outcome (stage 0 and 1) for anterior, posterior, apical and final stage of POP at discharge respectively. For 17 patients, 17 patients, 15 patients and 15 patients had the stage of anterior, posterior, apical and final stage of POP was stage one at third months. However, most studies have focused on anatomical success without considering symptoms and the quality of life (QOL) of the patient. In most studies in this field, outcomes of surgery have been assessed using questionnaires evaluating the efficacy of treatment regarding symptoms, sexuality and quality of life. National Institutes of Health (NIH) Workshop on Standardization of Terminology for Pelvic Floor Disorders recommended the following definitions for treatment success: 'optimal anatomical outcome' (POP-Q stage 0) and 'satisfactory anatomical outcome' (POP-Q stage I). However, $75 \%$ of women presenting for annual gynecological examination without symptoms of POP will not meet the definition of 'optimal anatomical outcome' and almost $40 \%$ will not meet the definition of 'satisfactory anatomical outcome' $[5,7]$.

\section{Conclusion and Recommendation}

Out of all patients presented with POP, nearly all of them treated with vaginal hysterectomy which accounts high prevalence of VAGH. We recommed physicians to do VAGH on case by case bases to reduce such number of surgical procedure. More than half were sexually active, and lived with POP for more than 120 months. Women with POP should consult physicians and start follow up at earlier time. More than two-third were presented at the final stage of POP with stage four. However, less than half presented with stage four for apical POP.The procedure took two to three hours for nearly all women in which the approach is vaginally for all. For almost all patients anterior repair with colpo-suspension, anterior repair, posterior repair and perineorraphy done.

However, for no one open uterosacral ligament suspension and open abdomino-sacrocolpopexy done. Four of patients were faced post-operative complication, three faced post-operative hemorrhage and four of them face problem of urinary retention which are all categorized as an unfavorable outcome. Near to all of women had favorable outcome (stage 0 and 1) for anterior, posterior, apical and final stage of POP at discharge. For some patients the final stage of POP was stage one at third months of follow up. Based on this findings, we recommend physicians to follow case based surgical techniques of VAGH to treat POP taking care of the issues at diagnosis. Patients with POP should come earliar for the services and awarness should be created. Physicians should do their level best to reduce the observed level of complication.

\section{Declaration}

\section{Acknowledgment}

We would like to express our deepest gratitude and appreciation the hospital registry, health professionals working at Obstetrics and gynecology department of JUMC. We also aknowledge Jimma University-Institute of health-IRB for securing ethical letter and JU for the fund provided.

\section{Ethics approval and consent to participate}

Ethical clearance and an approval letter obtained from Jimma University institute of health-institutional reviewing board, then support letter obtained from JUMC administrative office. Confidentiality was maintained by using anonymous codes and the patients' chart number.

\section{Consent to publish}

All parties involved agreed to publish on international peer reviewed journal. During data abstraction, all concerned body informed and agreed on the major objective of the study which is for accademic purpose including publication.

\section{Availability of data and materials}

The datasets used and/or analyzed during the current study are available. The SPSS (software) which is completed with raw dataset can be also shared. All data generated or analyzed during this study are included in this manuscript.

\section{Competing/Conflict of Interest}

All authors declare that they have no any financial and nonfinancial competing interests. None of the authors of this paper has a financial or personal relationship with other people or organizations that could inappropriately influence or bias the content of the paper. It is to specifically state that "No Competing interests are at stake and there is No Conflict of Interest" with other people or organizations that could inappropriately influence or bias the content of the paper.

\section{Authors' Contributions}

AW and YS had made substantial contributions to conception and design, analysis and interpretation of data including manuscript preparation. Both equally worked a lot in acquisition of data and reviewed the manuscript for the intellectual content. All authors read and approved the final manuscript. 


\section{References}

1. Johnson N, Barlow D, Lethaby A, Tavender E, Curr E, et al. (2006) Surgical approach to hysterectomy for benign gynecological disease. Cochrane Database Syst Rev 19(2): CD003677.

2. Samuelsson EC, Victor AFT, Tibblin G, Svärdsudd KF (1999) Signs of genital prolapse in Swedish population of women 20 to 59 years of age and possible related factors. Am J Obstet Gynecol 180(2 pt 1): 299-305.

3. Milsom I (2000) The prevalence of urinary incontinence. Acta Obstet Gynecol Scand 79(12): 1056-1059.

4. Olsen AL, Smith VJ, Bergstrom JO, Colling JC, Clark AL, et al. (1997) Epidemiology of surgically managed pelvic organ prolapse and urinary incontinence. Obstet Gynecol 89(4): 501-506.

5. Swift SE (2000) The distribution of pelvic organ support in a population of female subjects seen for routine gynecologic health care. Am J Obstet Gynecol 183(2): 277-285.

6. Prolapse CI (1995) Dewhurse's text book of obstetrics and gynaecology for postgraduates. In: Whitfield CR (ed), Oxford: Blackwell Science, USA.

7. Weber AM, Abrams P, Brubaker L, Cundiff G, Davis G, et al. (2001) The standardization of terminology for researchers in female pelvic floor disorders. Int Urogynecol J Pelvic Floor Dysfunct 12(3): 178-186.

8. Barber MD, Brubaker L, Nygaard I, Wheeler TL, Schaffer J, et al. (2009) Defining success after surgery for pelvic organ prolapse. In: $2^{\text {nd }}(e d n)$, Obstet Gynecol 114(3): 600-609.

9. Williams BFP (1966) Surgical treatment for uterine prolapse in young women. Am J Obstet Gynaecol 95(7): 967-971.

10. Richardson DA, Scotti RJ, Ostergard DR (1989) Surgical management of uterine prolapse in young women. J Reprod Med 34(6): 388-392.

11. Maher CF, Cary MP, Slack CJ, Murray CJ, Milligan M, et al. (2001) Uterine preservation or hysterectomy at sacrospinous colpopexy for uterovaginal prolapse? Int Urogynecol J Pelvic Floor Dysfunct 12(6): 381-384.
12. Hefni M, El-Toukhy T, Bhaumik J, Katsimanis E (2003) Sacrospinous cervicocolpopexy with uterine conservation for uterovaginal prolapse in elderly women: an evolving concept. Am J Obstet Gynecol 188(3): 645-650.

13. Brummen VHJ, Pol VDG, Aalders CI, Heintz AP, Vaart VDCH, et al. (2003) Sacrospinous hysteropexy compared to vaginal hysterectomy as primary surgical treatment for a descensus uteri: effects on urinary symptoms. Int Urogynecol J Pelvic Floor Dysfunct 14(5): 350-355.

14. Dietz V, Huisman M, Jong DJM, Heintz PM, Vaart VDCH, et al. (2008) Functional outcome after sacrospinous hysteropexy for uterine descensus. Int Urogynecol J Pelvic Floor Dysfunct 19(6): 747 752 .

15. Petros PE (2001) Vault prolapse II: restoration of dynamic vaginal supports by infracoccygeal sacropexy, an axial day-case vaginal procedure. Int Urogynecol J Pelvic Floor Dysfunct 12(5): 296-303.

16. Neuman M, Lavy Y (2007) Conservation of the prolapsed uterus is a valid option: medium term results of a prospective comparative study with the posterior intravaginal slingplasty operation. Int Urogynecol J Pelvic Floor Dysfunct 18(8): 889-893.

17. Dietz V, Koops SSE, Vaart VDCH (2009) Vaginal surgery for uterine descent; which options do we have? A review of the literature. Int Urogynecol J Pelvic Floor Dysfunct 20(3): 349-356.

18. Kulseng-Hanssen S, Borstad E (2003) The development of a questionnaire to measure the severity of symptoms and the quality of life before and after surgery for stress incontinence. BJOG 110(11): 983-988.

19. Nygaard IE, McCreery R, Brubaker L, Connolly A, Cundiff G, et al. (2004) Abdominal sacrocolpopexy: a comprehensive review. Obstet Gynecol 104(4): 805-823.

20. Mojgan P, Ingrid M, Löfgren M (2009) Outcomes of vaginal hysterectomy for uterovaginal prolapse: a population-based, retrospective, crosssectional study of patient perceptions of results including sexual activity, urinary symptoms, and provided care. BMC Women's Health 9: 9.

\section{Your next submission with Juniper Publishers will reach you the below assets}

- Quality Editorial service

- Swift Peer Review

- Reprints availability

- E-prints Service

- Manuscript Podcast for convenient understanding

- Global attainment for your research

- Manuscript accessibility in different formats

( Pdf, E-pub, Full Text, Audio)

- Unceasing customer service

Track the below URL for one-step submission https://juniperpublishers.com/online-submission.php 